\title{
Inhaler Characteristics in Asthma
}

\author{
Martyn Francis Biddiscombe and Omar Sharif Usmani \\ Airway Disease Section, National Heart and Lung Institute, Imperial College London, and Royal Brompton Hospital, London, UK
}

DOI: https://doi.org/10.17925/ERPD.2017.03.01.32

\begin{abstract}
$\mathrm{T}$ he history of inhaled therapy goes back a surprisingly long way. More than 4,000 years ago, in India, the vapour of plants from the nightshade family placed on hot bricks was inhaled to alleviate breathing difficulties. The bronchodilators, derived from these plants, and compounds related to them, have played a significant part in therapeutic aerosol delivery over the years and remain important in the treatment of lung diseases today. The development of inhaled therapy has accelerated over the past 60 years with the arrival of the first truly portable inhaler in 1956 to relieve the symptoms of asthma. Initially, only bronchodilators were delivered from these devices, but as the true nature of asthma was revealed, inhaled corticosteroids were introduced to treat the underlying inflammation that is a major component of asthma. Further advances have led to long-acting bronchodilators becoming available, and combination therapies containing both longacting bronchodilators and corticosteroids in one inhaler. Asthma therapy has come a long way in a comparatively short time with over 230 device and drug combinations available for treating the disease. However, despite enormous investment asthma remains a huge healthcare problem. The number of people with asthma continues to grow with over 300 million people affected worldwide and 250,000 annual deaths attributed to the disease. It affects people of all ages and has a varying degree of severity. In this article, we look at the ideal characteristics for asthma inhalers and highlight some of the most important reasons for the failure of current asthma treatments.
\end{abstract}

\section{Keywords}

Asthma, inhaler, pressurised metered dose inhaler (pMDI), dry powder inhaler (DPI), nebuliser, soft mist inhaler (SMI), inhaled corticosteroid (ICS), device chracteristics, patient adherence

Disclosure: Martyn Francis Biddiscombe has received industry-academic funding from Boehringe Ingelheim, Chiesi and GlaxoSmithKline. Omar Sharif Usmani has received industry-academic funding from Boehringer Ingelheim, Chiesi, Edmond Pharma, GlaxoSmithKline, Mundipharma International, and has received consultancy or speaker fees from AstraZeneca, Boehringer Ingelheim, Chiesi, Cipla, Edmond Pharma, Boehringer Ingelheim, Chiesi, Cipla, Edmond Pha
GlaxoSmithKline, Napp, Novartis, Mundipharma GlaxoSmithKline, Napp, Novartis, Mundipharma
International, Pearl Therapeutics, Roche, Sandoz, Takeda, UCB, Vectura and Zentiva. No funding was received for the publication of this article.

Compliance with Ethics: This study involves a review of the literature and did not involve any studies with human or animal subjects performed by any of the authors.

Authorship: All named authors meet the International Committee of Medical Journal Editors (ICMJE) criteria for authorship of this manuscript, take responsibility for the integrity of the work as a whole and have given final approval to the version to be published.

open Access: This article is published under the Creative Commons Attribution Noncommercial License, which permits any non-commercial use, distribution, adaptation and reproduction provided the original author(s) and source are given appropriate credit.

Received: 7 April 2017

Accepted: 23 May 2017

Citation: EU Respiratory \& Pulmonary Diseases, 2017;3(1):32-7

Corresponding Author: Martyn Francis Biddiscombe Airway Disease Section, Imperial College London, National Heart and Lung Institute, Dovehouse Street London SW3 6LY, UK. E: m.biddiscombe@imperial.ac.uk
Inhalation therapy has long been recognised as the optimal mode of treatment for the majority of patients with asthma and has played a pivotal role in their management for decades. ${ }^{1}$ The ability to target drug therapy directly to the site of disease within the lungs maximises local efficacy whilst minimising systemic exposure. Much smaller doses are necessary compared with oral and intravenous treatments reducing the risk of side effects. However, despite huge investment in new asthma drugs and inhalers over the past 30 years, disease control is still unsatisfactory. ${ }^{2}$ Part of the explanation lies with the poor response of certain types of asthma to current treatment.

Asthma is a highly complex and challenging chronic inflammatory disease of which, despite significant breakthroughs in recent years, our understanding is still far from complete. Indeed, due to its heterogeneous nature, the word asthma may in the future be considered just an umbrella term to define several different phenotypes. ${ }^{3}$ Other factors such as not treating comorbidities or poor targeting of inhaled drugs to distal lung regions may also contribute to poor disease control. ${ }^{4}$ One of the biggest factors for poor disease control is the patient's inability to master the use of their inhalers leading to the effectiveness of the treatments being greatly reduced. Indeed, the patient's ability to use their device correctly should be a key consideration in their therapeutic management, according to the European Respiratory Society. ${ }^{5}$

The aims of asthma therapies are to alleviate symptoms by minimising exacerbations and controlling inflammation, and in Europe today there are more than 230 different device/drug combinations of inhaled therapy and many of these are available for the treatment of asthma. ${ }^{6}$ The focus of this article is to review the literature regarding current and new inhaler characteristics for treating asthma and investigate the obstacles that must be overcome in order for patients to gain the full benefit from their inhaler. The main inhaler designs will be discussed as well as the most desirable characteristics of the aerosol discharged from the inhaler. We also discuss the reasons why inhaled therapy is not as effective as it could be.

\section{Desirable inhaler characteristics for treating asthma}

Traditionally, there are three main categories of inhaler devices used to treat asthma. These are the pressurised metered dose inhalers (pMDIs), dry powder inhalers (DPIs) and nebulisers. Numerous drug therapies are available in combination with these devices including short-acting $\beta_{2}$-agonists and long-acting $\beta_{2}$-agonists (LABA); short-acting muscarinic antagonists and long-acting muscarinic antagonists (LAMA); inhaled corticosteroids (ICS); and dual combination 
therapies of ICS/LABA and LAMA/LABA. Recently, triple therapy combining LABA/LAMA/ICS has been proposed primarily for patients with chronic obstructive pulmonary disease (COPD) who have concomitant asthma with frequent exacerbations.? A more recent addition to the inhaler family is the soft mist inhaler (SMI). It is an entirely new type of portable device that operates in a different way from both the pMDI and DPI, but currently only one such device is available. ${ }^{8}$

Asthma inhalers should be intuitive and easy to use by patients as it is often their inability to use the device that hinders adequate asthma control. Patient preference should be taken into account as it may have an effect on adherence to treatment. The ideal inhaler should be capable of delivering a predictable and consistent lung dose giving the desired clinical effect, while minimising side effects. It should also be independent of the patient's airflow, if possible, and all this should be achieved at a reasonable cost. 9,10

Delivering a sufficient dose of drug to the lungs is not easy, as the lungs have evolved to repel inhaled foreign substances in order to keep the airways clear for its primary purpose of gas exchange. The patient must first overcome the unnatural sensation of drawing a solid or liquid aerosol into their lungs. Once inhaled, the dose of drug must bypass the upper airways without significant impaction losses and then be carried by the inhaled airstream to the bronchial region and beyond, while avoiding any disease-related obstructions. A number of factors come into play when targeting the site of action in the airways. Some of these are human factors and some are associated with the physical properties of the aerosol itself. Human factors related to inhaler use can significantly influence the probability of correct medication use.

Of the human factors, the patient's ability to use their device is usually, but not always, controllable with training. However, this is often neglected and it is assumed that the patient needs only basic training. In reality, regular checking of inhalation technique is crucial, as correct inhalation is one of the cornerstones of successful asthma management. This point is underlined by a recent study based on data from a multicentre crosssectional study of adults with asthma (iHARP). ${ }^{11,12}$ A number of critical errors in inhaler use were identified which are related to an increased rate of asthma exacerbations. The study highlighted the importance of good training as part of primary and secondary care management to reduce the incidence of critical errors by patients.

The diseased state of the lung is a major factor which can prevent the drug dose penetrating to the site of action. As most asthma therapy is topically acting, the inhaler is of little use if it can only deliver a dose to the healthy part of the lungs while the diseased part goes untreated. ${ }^{13}$ Therefore, the physical characteristics of the discharged aerosol dose are as vital for a successful outcome as the pharmacodynamics of the drug itself. Particle size is the most important physical property of the aerosol cloud and is an important determinate of how far into the airways a dose can be delivered. This is often defined by the metric, fine-particle dose (FPD), which represents the proportion of the emitted dose contained within aerosol particles smaller than $5 \mu \mathrm{m}$. Particles of this size are considered to have the greatest potential for penetrating and depositing in the adult lungs. ${ }^{5} \mathrm{~A}$ frequent goal for inhaler designers is to achieve a mass median aerodynamic diameter of 2-3 um. ${ }^{14}$ Small drug particles have been shown to be able to penetrate further into the lungs than large particles, and these are also less likely to be affected by the disease severity of the lungs and the patient's inhalation flow rate. ${ }^{15}$ However, the chosen particle size will depend on which part of the airways is to be targeted.
Figure 1: Lung deposition images, obtained using gamma scintigraphy, illustrate how aerosol particle size influences lung deposition ${ }^{15}$
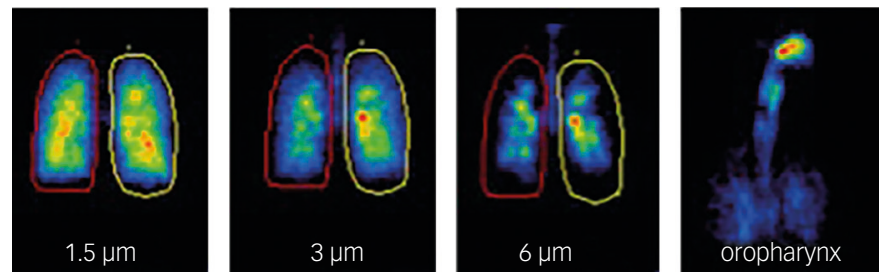

High deposition in the upper airways can lead to reduced lung dose and poor efficacy. Reprinted with permission of the American Thoracic Society. Copyright @ 2017 American Thoracic Society. Images sourced from: Usmani OS, Biddiscombe MF, Barnes PJ, 2005.15

Figure 2: Effect of fast inhalation flow rate on ( $>60 \mathrm{~L} / \mathrm{min})$ lung deposition for three different aerosol particle sizes (blue bars) compared with slow (30 L/min) inhalation (purple bars) on aerosol deposition ${ }^{15}$

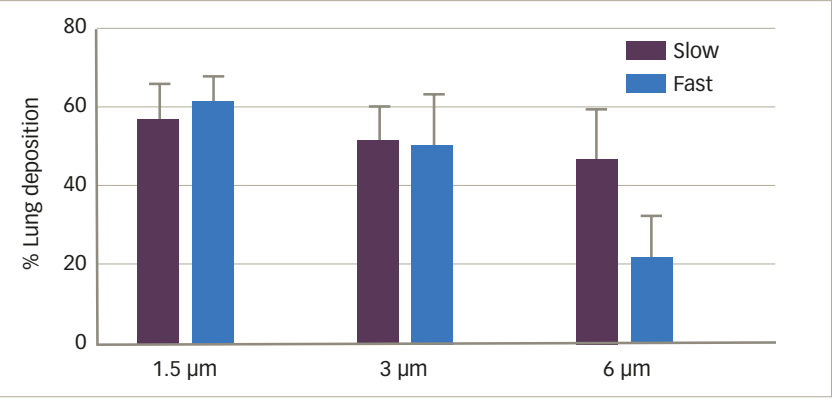

Data sourced from: Usmani OS, Biddiscombe MF, Barnes PJ, 2005.15

Figure 1 illustrates the influence of aerosol particle size on drug deposition in the lungs. Small particles of size $1.5 \mu \mathrm{m}$ were more uniformly distributed throughout the entire lungs than large particles of size $6 \mu \mathrm{m}$. Figure 2 shows the effect of inhalation flow rate on lung deposition. Small particles were less affected by inhalation flow than large particles.

To fully treat asthma adequate drug must be deposited in both the central and peripheral airways as it is known that both are involved in the disease. ${ }^{16}$ The role of the latter was for many years neglected due to the difficulty in measuring its contribution to the overall asthma effect. This has now changed due to the widespread availability of measures of the function of small airways such as impulse oscillometry and the multiple-breath nitrogen washout test, as well as innovation in imaging techniques. ${ }^{17}$ The distal airways contribute little to airflow obstruction in healthy lungs as the combined crosssectional area of the airways increases rapidly in the respiratory zone (generations 16-23). However, it has been shown that distal airways are the major determinant of airflow obstruction in asthma. ${ }^{18,19}$ Inflammation in the distal airways (those with internal diameters $<2 \mathrm{~mm}$ ) is usually more intense in severe and uncontrolled asthma and these airways are poorly served by conventional asthma inhalers, which deliver aerosols of 3-5 $\mu \mathrm{m}$ particles resulting in impaction losses in regions proximal to this inflammation. ${ }^{20}$ In order to reduce impaction losses, aerosols delivering extra-fine particles are better able to negotiate severe obstructions. It has been shown in real-life primary care studies that small drug particles of ICS monotherapy and dual ICS/LABA combination therapy improve disease control in asthma and patients with COPD better than large drug particles. ${ }^{19,21}$ Table 1 summarises the desirable characteristics of asthma inhalers. 
Table 1. Desirable characteristics of asthma inhalers

\begin{tabular}{|c|c|}
\hline Characteristic & Comments \\
\hline $\begin{array}{l}\text { Should be intuitive and } \\
\text { easy to use }\end{array}$ & $\begin{array}{l}\text { Patients are more likely to use the device if it is easy } \\
\text { to learn to use. The most effective devices are those } \\
\text { that the patient is familiar with and knows how to } \\
\text { use correctly. }\end{array}$ \\
\hline $\begin{array}{l}\text { Easy to use in an } \\
\text { emergency }\end{array}$ & $\begin{array}{l}\text { Multidose devices are quicker to use particularly } \\
\text { during an exacerbation. Single-dose inhalers take } \\
\text { longer to prepare as the dose must be loaded into } \\
\text { the device immediately before use. }\end{array}$ \\
\hline $\begin{array}{l}\text { Capable of delivering } \\
\text { a predictable and } \\
\text { consistent lung dose }\end{array}$ & $\begin{array}{l}\text { The device must be able to deliver a reproducible } \\
\text { dose each time it is used. The patient must be } \\
\text { confident that the dose has been given. If there is } \\
\text { any doubt they may try to take it again or not at all. }\end{array}$ \\
\hline $\begin{array}{l}\text { Delivers the dose in small } \\
\text { aerosol particles/droplets } \\
\text { with a high fine particle } \\
\text { dose }\end{array}$ & $\begin{array}{l}\text { Asthma is a disease of both the small and large } \\
\text { airways. Doses delivered as finer aerosols are } \\
\text { capable of penetrating to all parts of the lungs } \\
\text { allowing the optimal treatment of the small airways } \\
\text { as well as the large. }\end{array}$ \\
\hline $\begin{array}{l}\text { Delivers a slow aerosol } \\
\text { cloud }\end{array}$ & $\begin{array}{l}\text { It is much easier for the patient to inhale the dose } \\
\text { without impaction losses in the throat if the dose is } \\
\text { delivered as a slow-moving cloud over a relatively } \\
\text { long period ( } 1-2 \text { seconds). }\end{array}$ \\
\hline Minimises side effects & $\begin{array}{l}\text { Low impaction losses in the upper airways ensures } \\
\text { most of the dose is delivered to the lungs and not } \\
\text { swallowed, minimising side effects. }\end{array}$ \\
\hline $\begin{array}{l}\text { A way of indicating how } \\
\text { many doses are left }\end{array}$ & $\begin{array}{l}\text { Most modern inhalers include a dose counter of } \\
\text { some sort enabling the patient to plan ahead and } \\
\text { obtain a replacement well before the current one } \\
\text { runs out. This is not always the case for pMDIs as } \\
\text { integrated dose counters are difficult to implement } \\
\text { in these devices. }\end{array}$ \\
\hline Reasonable cost & $\begin{array}{l}\text { If the device is too expensive it will not be } \\
\text { prescribed to the patient. }\end{array}$ \\
\hline
\end{tabular}

\section{Inhaler devices for asthma therapy \\ Pressurised metered dose inhalers}

Probably the single most important development in inhaler technology was the introduction of the pMDI in 1956 by Riker Laboratories, Inc., (now 3M Drug Delivery Systems). ${ }^{22}$ This is considered by many to have been the start of the modern inhaler era, but the pMDI is often taken for granted as it is hard to imagine a time before it was available.

However, despite showing its age, the pMDI is still the most widely prescribed inhalation device for treating asthma. ${ }^{6}$ Outwardly, the device is still recognisable from its early incarnations and its mode of action has not changed significantly. It relies on a metering valve to accurately and reproducibly deliver a known volume of propellant and micronised drug at each valve actuation. However, internally it has undergone significant device engineering and formulation changes resulting in a new generation of pMDIs. Asthma therapies delivered from these devices have also dramatically improved since the first devices with the arrival of corticosteroids and $\beta_{2}$-agonists allowing better disease management. Despite these important improvements the pMDI still retains its most endearing features. It is small, portable, multidose and relatively affordable compared to most competing inhalation delivery systems. However, while considered by many to be the ideal inhaler, there are a number of issues that make the pMDI far from ideal. Firstly, the high discharge speed of the aerosol plume means that much of the dose deposits into the back of the throat before it can reach the lungs. Associated with this throat impaction is the so-called 'cold Freon' effect which may be uncomfortable to the patient. Secondly there is a requirement for the patient to co-ordinate the actions of inhaling and actuating the inhaler in order for at least part of the dose to penetrate to the lungs. Thirdly, the essential components of pMDIs, propellants, have caused their fair share of problems for the pharmaceutical industry. This is because in the early 1990s, the pharmaceutical industry was forced to invest heavily to find replacements for chlorofluorocarbon (CFC) propellants, following the approval of the Montreal protocol in $1987,{ }^{23}$ calling for their global withdrawal because of the damage they were causing to the environment. Besides replacing CFC propellants, this investment led to more efficient pMDIs due to better propellants becoming available and improvements in PMDI technology. ${ }^{24}$ These new generations of pMDIs use hydrofluoroalkane (HFA) propellants. While some of the HFA devices were matched to their CFC counterparts on a dose-for-dose basis, ${ }^{25}$ the switch to HFA inhalers also offered the opportunity to completely redesign the pMDI. New formulations of pMDIs can dispense aerosols with smaller particle sizes and lower plume velocities. ${ }^{26}$ These factors result in a decrease of upper airway impaction and an increase in lung deposition of particles, particularly to the smaller airways, compared with CFC pMDIs. ${ }^{27,28}$ This provided the opportunity to improve the performance of $\beta_{2}$-agonist pMDIs, but crucially facilitated ICS delivery to both large and small airways. ${ }^{19}$ Another advantage of HFA propellants are that they are warmer than CFC propellants and they partly overcome the 'cold Freon' effect that caused some patients to stop inhaling as soon as the propellants hit the back of the throat. ${ }^{29}$ Not all HFA pMDIs are the same as they can be formulated with the drug insoluble in the formulation (suspension pMDI) or completely dissolved in the formulation (solution pMDI). ${ }^{30}$ Solution pMDIs contain a more homogeneous formulation, which does not require shaking prior to use, and deliver aerosols of smaller particle sizes. ${ }^{19}$ However, in order to achieve solubility of the drug, a cosolvent such as ethanol must be added to the formulation.

The most common difficulty encountered with standard pMDIs is poor co-ordination between actuation and inhalation resulting in the patient receiving little or no dose. Add-on devices called spacers or holding chambers attach to the pMDI mouthpiece and act as a reservoir into which the aerosol plume is actuated. Some spacers are simple tube extensions attached to the pMDI mouthpiece with no valves, while others contain a one-way valve to prevent escape of the aerosol until inhalation. ${ }^{31}$ The spacer provides an increased distance between the pMDI actuator and the patient's mouth slowing the aerosol plume significantly and enabling them to inhale the dose directly from the spacer without co-ordination. In addition, the particle size decreases due to the evaporation of propellants leading to increased deposition in the lungs. ${ }^{31}$ Infants and small children especially find using a pMDI difficult and some spacers are specially designed for them and may be used with facemasks instead of a mouthpiece. ${ }^{9}$ They are also useful for treating elderly and frail patients. While spacers are useful additions to pMDIs, allowing improved drug-delivery to the lungs, to many their obvious disadvantage is their size making the inhaler less portable and compact to use. This may make them less appealing to patients, especially among young people who may be too self-conscious to use them in public, leading to poorer adherence.

One recent study has challenged the assumption that spacers will always improve the effectiveness of pMDIs. ${ }^{32}$ Using historically matched cohorts of patients with asthma they found no evidence that using a spacer with fine and extra-fine ICS pMDIs offered any improvement in asthma outcomes compared to using the pMDI on its own. One possible explanation for this is that fine and extra-fine aerosols are easier to 
inhale into the lungs than standard coarser aerosols due to their small size, resulting in comparable FPDs with and without a spacer.

Breath-actuated pMDIs have been developed as an alternative means of overcoming the co-ordination problem. ${ }^{5} \mathrm{~A}$ number of different breathactuated devices are available. ${ }^{33}$ They contain a conventional pressurised canister which is actuated by a spring mechanism. The devices sense the patient's breath and trigger the spring to release the dose as the patient inhales allowing the two actions to be automatically co-ordinated. ${ }^{34,35}$ They have been shown to improve lung deposition and clinical efficacy in patients who have co-ordination difficulty with a standard pMDI. ${ }^{36}$

\section{Dry powder inhalers}

DPIs are small portable devices that, as the name implies, deliver the medication as a dry powder often with the addition of excipients such as lactose in order to aid dispersion. They do not require propellants to generate the aerosol and the energy for releasing and dispersing the powder into an aerosol is derived from the inhaled airstream of the patient. For this reason, it is important that the patient is able to take a sufficiently deep breath with an inspiratory flow rate that is high enough to disperse and deliver the powder. If the inspiratory flow is suboptimal and the minimum energy threshold is not reached, the mass of drug emitted may be reduced and the drug particle size may be increased. Each device has a different resistance with a different minimum energy threshold. ${ }^{37}$ Ideally, the device and drug should be selected carefully to suit the patients' needs and abilities as many patients with respiratory disease may not reach these optimal conditions to achieve effective drug delivery into their lungs.

Since the early 1970s the number of DPI devices available has mushroomed with an ever-expanding assortment of inhaler designs and drug combinations. ${ }^{38}$ Their use has rapidly increased despite the widespread acceptance that the lung is more naturally adapted to deal with moisture than powder. The main advantages of DPIs are that they are portable and breath-actuated, so patients do not have to co-ordinate actuation with inhalation. In general, DPIs deliver a similar range of asthma drugs to pMDIs. Despite the many different brands of DPIs there are two main types available: (1) devices that use single-dose capsules which must be loaded manually each time they are required by the patient:;8 (2) multidose devices, where the drug is either contained as a bulk formulation in a reservoir, which is metered by the patient during use, or premetered factory-dispensed doses packaged inside blisters within the device. ${ }^{539}$ Some devices are reusable while others are not.

However, the multiplicity of different DPIs available can be a disadvantage. The overwhelming number of devices can result in fatigue on the part of the healthcare professional when choosing the right inhaler device for their patient. ${ }^{40}$ The patient themselves can be even more confused. ${ }^{34}$ Unlike the PMDI where, with minor variations, each brand is operated in the same way, different DPI devices require different techniques to prepare and inhale the dose. Each device has different resistance requiring the patient to either increase or decrease their inhalation effort in order to obtain optimal dose. ${ }^{41}$ This can cause confusion among patients who are used to one device but are switched to another device. Even though it may deliver the same drug it may look entirely different and be operated in a totally different way. Elderly patients, in particular, may struggle if the device requires several complex steps or is awkward to load. One study compared the ability of elderly patients to use a multidose device compared to another device that required a capsule to be loaded each time it was used. ${ }^{22}$ They found approximately $60 \%$ of elderly patients were able to use the multidose device successfully compared with less than $30 \%$ of the patients for the device that required the loading of a capsule each time. All these factors have a bearing on patient adherence.

As for all inhaler devices particle size is an important determinant of how efficiently the dose can be delivered to the lungs. For a DPI, the particle size distribution depends on the patient's ability to draw a particular airflow through the device to create the shear force that disperses the particles. In general, a higher shear force leads to a higher percentage of smaller particles. ${ }^{38}$ DPIs have the advantage over pMDIs that they do not require co-ordination between actuation and inhalation. However, they are much more demanding of the patient's inspiratory effort and therefore may not be suitable for all patients.

\section{Nebulisers}

Nebulisers use the energy from compressed air, ultrasonic sound waves or a vibrating mesh to convert medical solutions and suspensions into inhalable aerosol vapour. ${ }^{43}$ They are suitable for delivering high doses of drug or drug mixtures and new drugs not formulated for pMDIs or DPIs. One advantage for patients who have difficulty in using pMDIs and DPIs is that no special inhalation technique is required for optimum delivery other than tidal breathing. This makes them an alternative to a pMDI with spacer in emergency situations such as during an acute asthma exacerbation in an ambulance or in hospital. ${ }^{44}$ They are also useful for infants and children where the aerosol can be delivered via a facemask. ${ }^{45}$

The most common type of nebuliser is the jet or pneumatic nebuliser, which uses compressed air to generate the aerosol. They are relatively cheap but because of their need for compressed air they can be quite bulky and noisy. Jet nebulisers are also quite slow compared with newer nebuliser devices and have high residual volumes leading to inefficiency and waste of expensive medications. ${ }^{46}$ Ultrasonic nebulisers use ultrasonic sound, generated by a vibrating piezoelectric crystal, to break up solutions into inhalable vapours. They operate more quickly than jet nebulisers but they are not suitable for suspensions. Their main drawback is that the piezoelectric crystal can heat the liquid drug in the reservoir. Vibrating mesh nebulisers are a more recent device that overcomes many of the disadvantages of the other nebulisers. They force liquid medications through precisely formed multiple apertures in a mesh or aperture plate in order to generate aerosol. The mesh contains apertures that control the size and flow of the aerosolised particles. They are more portable and their lower residual volume and lower plume velocity with a high FPD allow improved drug delivery to the lungs. ${ }^{47}$ They are also virtually silent. Vibrating mesh devices can be either active or passive systems. In active devices an aperture plate vibrates at a high frequency. Solution is drawn through the apertures in the plate to generate the aerosol. In passively vibrating devices the mesh is attached to a transducer horn. The solution is forced through the mesh to create an aerosol by the vibrations of a piezoelectric crystal that are transmitted via the transducer horn. ${ }^{5}$ Unfortunately, standard nebulisers may still result in highly variable lung doses. This is due to the variable inhaled volumes and flow rates as the patient breathes by relaxed spontaneous breathing. Aerosol is generated when the patient is exhaling as well as when they are inhaling and the portion not delivered to the lungs is wasted. The developments of so-called 'intelligent' nebulisers, which can adapt their output to the patient's breathing pattern, have been developed in response to the need for more precise drug delivery. Intelligent devices combine a microprocessor and software with an aerosol generator and are able to monitor the patient's breathing pattern and can continuously adjust the delivery of nebulised medication accordingly. They can control 
Table 2. Advantages and disadvantages of the main types of asthma inhalers

\begin{tabular}{|c|c|c|}
\hline Device & Advantage & Disadvantage \\
\hline pMDI & $\begin{array}{l}\text { - } \text { Compact } \\
\text { - Portable } \\
\text { - Multidose } \\
\text { - Metered dose } \\
\text { - Familiarity by patient }\end{array}$ & $\begin{array}{l}\text { - Co-ordination required } \\
\text { - High plume speed } \\
\text { - High deposition in mouth and pharynx } \\
\text { - 'Cold Freon' effect } \\
\text { - Dose counter not always available } \\
\text { - Contains propellants that are greenhouse gases }\end{array}$ \\
\hline pMDI + spacer & $\begin{array}{l}\text { - } \text { No co-ordination necessary } \\
\text { - Holds aerosol for short period prior to inhalation } \\
\text { - Slows down aerosol plume } \\
\text { - Reduces deposition in mouth and pharynx } \\
\text { - Can improve lung deposition }\end{array}$ & $\begin{array}{l}\text { - } \text { Bulky to carry around } \\
\text { - Some dose lost in spacer } \\
\text { - Static charge may be a problem } \\
\text { - Requires regular cleaning } \\
\text { - Contains propellants }\end{array}$ \\
\hline Breath-actuated pMDI & $\begin{array}{l}\text { - No co-ordination required } \\
\text { - } \text { Compact } \\
\text { - Portable } \\
\text { - Breath-actuated }\end{array}$ & $\begin{array}{l}\text { - 'Cold Freon' effect } \\
\text { - Minimum required flow to trigger } \\
\text { - Contains propellants }\end{array}$ \\
\hline DPI & $\begin{array}{l}\text { - } \text { Breath-actuated } \\
\text { - } \text { Does not require propellants } \\
\text { - } \text { Multiple dose devices available } \\
\text { - } \text { Compact } \\
\text { - Portable } \\
\text { - Reproducible dose delivered }\end{array}$ & $\begin{array}{l}\text { - Multiple designs (may be confusing to patients) } \\
\text { - } \text { Requires patient to achieve a minimum inspiratory threshold to } \\
\text { generate dose } \\
\text { - Moisture-sensitive } \\
\text { - } \text { May be complicated to load } \\
\end{array}$ \\
\hline Nebulisers & $\begin{array}{l}\text { - Can be used to dispense drugs not available as PMDI or DPI } \\
\text { - Can deliver high doses of drug } \\
\text { - Delivery by tidal breathing } \\
\text { - Vibrating mesh devices are portable } \\
\text { - Intelligent nebulisers allow more efficient delivery }\end{array}$ & $\begin{array}{l}\text { - Jet and ultrasonic nebulisers require external energy source } \\
\text { - Older designs are very inefficient at delivery } \\
\text { - Long treatment times } \\
\text { - Newer devices are expensive }\end{array}$ \\
\hline Soft mist inhaler & $\begin{array}{l}\text { - Portable } \\
\text { - Multidose } \\
\text { - Slow mist generated over } 1.5 \text { seconds } \\
\text { - Fine aerosol droplets } \\
\text { - Easy to use }\end{array}$ & $\begin{array}{l}\text { - Only one device currently available } \\
\text { - Some co-ordination necessary }\end{array}$ \\
\hline
\end{tabular}

$D P I=$ dry powder inhaler; $\mathrm{PMDI}=$ pressurised metered dose inhaler

the delivery of medication to the first $50 \%$ of the inhalation phase of breathing based on an average of the most recent three breaths. ${ }^{4849}$ They can be instructed to switch off after a predetermined dose has been delivered and can provide operational logs regarding patient adherence to prescribed treatment. 45,47

\section{Soft mist inhalers}

Continued innovation in inhaler technology has led to a new class of inhaler device called SMIs.50 SMIs transform aqueous liquid solution to an inhalable vapour using the energy of a compressed spring inside the inhaler. ${ }^{1}$ They are multidose and portable devices that can potentially compete with MDIs and DPIs for convenience of use. SMIs have the additional advantages that they do not require propellants or the patient's inspiratory effort to generate the aerosol and generate a slow mist aerosol over approximately 1.5 seconds. This makes it easier for the patient to co-ordinate actuation with inhalation and has the potential to reduce impaction in the upper airways and improve the dose to the lungs if the patient adheres to the recommended slow deep inhalation manoeuvre. It does require the patient to twist the base of the device in order to load the spring, which may be fiddly for elderly patients with rheumatism. Only one such device is currently available although this may change in the future. ${ }^{50}$ Table 2 summarises the advantages and disadvantages of each type of inhaler.

\section{Conclusions and Future Directions}

Inhaled medication has undoubtedly improved the quality of life of hundreds of millions of people since the invention of the first portable device. 'However, it is not all good news and significant challenges remain. Despite the availability of highly effective medication and comprehensive management guidelines, asthma control remains poor.51 Patient nonadherence to treatment contributes to this problem and healthcare professionals and caregivers can help to address this by reinforcing the importance of taking prescribed medications and regularly assessing the patient's inhalation technique at each contact opportunity.

What does the future hold for inhaled asthma therapy? Developments in treatment are expected to continue as new drugs and emerging technologies become more widely available. This may include personalised treatments for certain types of asthma not responding to the stepwise approach of the Global Initiative for Asthma (GINA) guidelines ${ }^{52}$ and treatments tailored to the specific composition of individual patient's airway inflammation. ${ }^{53}$ Inhaler technology will continue to innovate with 'intelligent' delivery systems allowing more precise targeting of specific areas of the lungs becoming more common.9.48 In addition, inhaler-based health monitoring devices providing feedback of inhaler use to patients and healthcare professionals offer the promise of improved treatment adherence and health outcomes. ${ }^{54}$ 
1. Stein $\mathrm{SW}$, Thiel $\mathrm{CG}$, The history of therapeutic aerosols: a chronological review, J Aerosol Med Pulm Drug Deliv, 2016; 29:1-22.

2. Demoly P, Gueron B, Annunziata K, et al., Update on asthma control in five European countries: results of a 2008 survey, Eur Respir Rev, 2010;19:150-7.

3. Corren J, Asthma phenotypes and endotypes: An evolving paradigm for classification, Discov Med, 2013;15:243-9.

4. Usmani OS, Barnes PJ, Assessing and treating small airways disease in asthma and chronic obstructive pulmonary disease Ann Med, 2012;44:146-56.

5. Laube BL, Janssens HM, de Jongh $F H C$, et al., What the pulmonary specialist should know about the new inhalation
therapies, Eur Respir J, 2011:37:1308-31.

6. Lavorini F, Corrigan CJ, Barnes PJ, et al., Retail sales of inhalation devices in European countries: so much for a global policy, Respir Med, 2011;105:1099-103.

7. Barnes PJ, Triple inhalers for obstructive airways disease: will they be useful?, Expert Rev Respir Med, 2011;5:297-300.

8. Patel KR, Pavia D, Lowe L, Spiteri M, Inhaled ethanolic and aqueous solutions via Respimat Soft Mist Inhaler are welltolerated in asthma patients, Respiration, 2006;73:434-40.

9. Newman S, Improving inhaler technique, adherence to therapy and the precision of dosing: major challenges for pulmor

drug delivery, Expert Opin Drug Deliv, 2014;11:365-78.
10. Lavorini $F$, The challenge of delivering therapeutic aerosols to . Lavorini F, The challenge of delivering therapeutic
asthma patients, ISRN Allergy, 2013;2013:102418.

11. Price DB, Román-Rodríguez M, McQueen RB, et al., Inhaler errors in the CRITIKAL study: type, frequency, and associatio with asthma outcomes, J Allergy Clin Immunol Pract, 20175:1071-81.e9

12. IHARP database. Available at: http://iharp.org/ (accessed 1 December 2016).

13. Verbanck S, Ghorbaniasl G, Biddiscombe MF, et al., Inhaled aerosol distribution in human airways: a scintigraphy-guided study in a 3D prin $2016: 29: 1-9$.

14. Lewis $\mathrm{D}$, Copley $\mathrm{M}$, Inhaled product characterization calculating particle-size distribution metrics, Pharm Tech, 2011;6:33-7. Avallable at. www.copleyscientific.com/files/ww/news/COP\%20

JOB\%2014_depsition, Buscono eposion and bronchodlator response as a function of beta2-agonist particle size, Am J Respir Crit Care Med

16. Usmani OS, Singh D, Spinola M, et al., The prevalence of small irways disease in adult asthma: a systematic literature review, Respir Med, 2016;116:19-27.

17. Biddiscombe MF, Usmani OS, The importance of imaging and physiology measurements in assessing the delivery 2012;3:1329-45.

18. Yanai M, Sekizawa K, Ohrui T, et al., Site of airway obstruction in pulmonary disease direct measurement of intrabronchia pressure, J Appl Physiol, 1992;72:1016-23.
19. Usmani OS, Small-airway disease in asthma: pharmacologica considerations, Curr Opin Pulm Med, 2015;21:55-67.

20. Burgel PR, Bourdin A, Chanez P, et al., Update on the roles of distal airways in COPD, Eur Respir Rev, 2009;18:80-95.

21. Postma DS, Roche N, Colice G, et al., Comparing the effectiveness of small-particle versus large-particle inhaled corticosteroid in COPD, Int I Chron Obstruct Pulmon Dis, 2014;9:1163-86

22. Thiel CG, From Susie's question to CFC-free: an inventor's perspective on forty years of MDI development and regulation Respir Drug Deliv, 1996;1:115-23.

23. Montreal protocol on substances that deplete the ozone layer, Treaty Doc, No. 10, 100th Congress, ILM 1987. Available at: ttps://treaties.un.org/doc/Treaties/1989/01/19890101\%20 03-25\%20AM/Ch_XXVII_02_ap.pdf

24. Stein SW, Sheth $\mathrm{P}$, Hodson PD, Myrdal PB, Advances in metered dose inhaler technology: hardware development, AAPS PharmSciTech, 2014;15:326-38

25. Ganderton D, Lewis D, Davies R, et al., Modulite: a means of designing the aerosols generated by pressurized metered dose inhalers, Respir Med, 2002;96:S3-8.

26. Leach $\mathrm{CL}$, The CFC to HFA transition and its impact on pulmonary drug development, Respir Care, 2005;50:1201-8.

27. Leach $\mathrm{CL}$, Lung deposition of hydrofluoroalkane-134a beclomethasone is greater than that of chlorofluorocarbon fluticasone and chlorofluorocarbon beclomethasone: a crossover study in healthy volunteers, CHEST, 2002;122:510-6.

28. Purewal TS, Gabrio BJ, Gray P, Plume characteristics of the sprayed dose from CFC and HFA metered dose inhalers, (1998:11:177-80.

29. Gabrio BJ, Stein SW, Velasquez DJ, A new method to evaluate plume characteristics of hydrofluoroalkane and chlorofluorocarbon metered dose inhalers, Int J Pharm,

30. Myrdal PB, Sheth P, Stein SW, Advances in metered dose inhale technology: formulation development, AAPS PharmSciTech, 2014; 15:434-55

31. Lavorini F, Fontana $G$, Targeting drugs to the airways: the role of spacer

32. Guilbert TW, Colice G, Grigg J, et al., Real-life outcomes for patients with asthma prescribed spacers for use with either extrafine- or fine-particle inhaled corticosteroids, A Allergy Clin

33. Lavorini F, Fontana GA, Usmani OS, New inhaler devices - the good, the bad and the ugly, Respiration, 2014;881:3-15.

34. Crompton GK, How to achieve good compliance with inhaled sthma therapy, Respir Med, 2004;98:S35-40.

35. Lenny J, Innes J, Crompton G, Inappropriate inhaler use: assessment of use and patient preference of seven inhalation

36. Gross G, Cohen R, Guy H, Efficacy response of inhaled HFA-albuterol delivered via the breath-actuated autohale inhalation device is comparable to dose in patients with asthma, J Asthma, 2003:40:487-95.
37. Dal Negro RW, Dry powder inhalers and the right things to remember: a concept review, Multidiscip Respir Med, 2015;10:1-4.

38. Atkins PJ, Dry powder inhalers: an overview, Respir Care, 2005;50:1304-12

39. O'Connor BJ, The ideal inhaler. design and characteristics to improve outcomes, Respir Med, 2004;98:10-6.

40. Virchow JC, Guidelines versus clinical practice - which therapy and which device?, Respir Med, 2004;98:28-34.

41. Azouz W, Chrystyn $\mathrm{H}$, Clarifying the dilemmas about inhalation techniques for dry powder inhalers: integrating science with clinical practice, Prim Care Respir J, 2012;21:208-13.

42. Moore AC, Stone S, Meeting the needs of patients with COPD: patients' preference for the Diskus inhaler compared with the Handihaler, Int J Clin Pract, 2004;58:444-50.

43. O'Callaghan C, Barry PW, The science of nebulised drug delivery, Thorax, 1997;52:S31-44.

44. Fergusson RJ, Stewart CM, Wathen CG, et al., Effectiveness of nebulised salbutamol administered in ambulances to patients with severe acute asthma, Thorax, 1995;50:81-2.

45. Berlinski A, Effect of mask dead space and occlusion of mask holes on delivery of nebulized albuterol, Respir Care, 2014;59:1228-32.

46. Fischer A, Stegemann J, Scheuch G, Siekmeier R, Novel devices for individualized controlled inhalation can optimize aeroso therapy in efficacy, patient care and power of clinical trials,

47. Ari A, Jet, ultrasonic, and mesh nebulizers: an evaluation of nebulizers for better clinical outcomes, Eurasian J Pulmonol, 2014;16:1-7.

48. Dhand $\mathrm{R}$, Intelligent nebulizers in the age of the internet: the I-neb adaptive aerosol delivery system, J Aerosol Med Pulm Drug Deliv, 2010;23:iii-

4. Rubin BK, Williams RW, Emerging aerosol drug delivery strategies: from bench to clinic, Adv Drug Deliv Rev, 2014;75:141-8.

50. Schürmann W, Schmidtmann S, Moroni P, et al., Respimat ${ }^{\mathbb{E}}$ Soft Mist'M inhaler versus hydrofluoroalkane metered dose inhaler: patient preference and satisfaction, Treat Respir Med

51. The Global Asthma Report 2014. Auckland, New Zealand: Global Asthma Network, 2014. Available at: www.globalasthmareport. org/resources/Global_Asthma_Report_2014.pdf (accessed 18

Global Initiative for Asthma (GINA), Global strategy for asthma management and prevention, 2017. Avallable

53. Wadsworth SJ, Sandford AJ, Personalised medicine and asthma diagnostics/management, Curr Allergy Asthma Rep, 2013;13:118-29.

54. Kikidis D, Konstantinos V, Tzovaras D, Usmani OS, The digita asthma patient: the history and future of inhaler based health monitoring devices, I Aerosol Med Pulm Drug Deliv, 2016:29:219-32. 